\title{
Nuclear and plastid transformation of Brassica oleracea var. botrytis (cauliflower) using PEG-mediated uptake of DNA into protoplasts
}

\author{
Gregory D. Nugent ${ }^{\mathrm{a}, 1}$, Seamus Coyne ${ }^{\mathrm{b}}$, Thi T. Nguyen ${ }^{\mathrm{a}}$, \\ Tony A. Kavanagh ${ }^{b}$, Philip J. Dix ${ }^{\mathrm{a}, *}$ \\ ${ }^{a}$ Biology Department, National University of Ireland, Maynooth, Co. Kildare, Ireland \\ ${ }^{\mathrm{b}}$ Department of Genetics, Trinity College Dublin, Ireland \\ Received 30 May 2005; received in revised form 27 July 2005; accepted 17 August 2005 \\ Available online 12 September 2005
}

\begin{abstract}
Most plastid transformation studies with tobacco, and all reports for other species (except tomato [G.D. Nugent, M. ten Have, A. van der Gulik, P.J. Dix, B.A. Uijtewaal, A.P. Mordhorst, Plastid transformants of tomato selected using mutations affecting ribosome structure. Plant Cell Rep. 24 (2005) 341-349]), have used biolistics for plastid transformation. However, nuclear transformation via biolistics has not been reported for any vegetable Brassica species so we used protoplast culture and PEG-mediated DNA uptake, to examine both nuclear and plastid transformation of cauliflower, an important vegetable Brassica. A vector containing genes for hygromycin resistance and $\beta$-glucuronidase activity (pGUS-HYG) was used for nuclear transformation, while plastid transformation utilised a vector (pZB1) containing $a c c D-r b c L$ plastome targeting regions cloned from Brassica napus (oil seed rape), and the selectable marker gene aadA, conferring resistance to spectinomycin. Protoplasts were embedded in agarose and selected on media containing hygromycin or spectinomycin. From five experiments, a single plastid transformant of the commercial cultivar Thalassa was obtained, whereas nuclear transformants were obtained at an absolute transformation frequency up to $1.3 \times 10^{-5}$. No spontaneous spectinomycin resistant mutants were observed in any plastid transformation experiments. PCR and Southern blot analysis confirmed the transgenic status of plants regenerated from the protoplast-derived calli.
\end{abstract}

(C) 2005 Elsevier Ireland Ltd. All rights reserved.

Keywords: Cauliflower; Plastid transformation; Nuclear transformation; Protoplast culture

\section{Introduction}

Plastid transformation is a recently developed technique suitable for both fundamental studies of plastid gene function (e.g. [2]), and many potential biotechnological applications such as herbicide, insect and disease resistance, abiotic stresses tolerance, edible vaccines, phytoremediation and biopharming [3-6]. The advantages of plastid transformation over nuclear transformation have been reviewed extensively (e.g. [4,7]) and include the potential for high-level production of foreign proteins, the containment of transgenes in most species due to

Abbreviations: BA, 6-benzyladenine; GUS, $\beta$-glucuronidase; 2iPN ${ }^{\circ}$-(2isopentenyl)-adenine; MS, Murashige and Skoog; NAA, $\alpha$-naphthalene acetic acid

* Corresponding author. Tel.: +353 1708 3836; fax: +3531 7083845 .

E-mail address: phil.dix@nuim.ie (P.J. Dix).

${ }^{1}$ Present address: Department of Biotechnology and Environmental Biology, RMIT University, Bundoora, Vic. 3083, Australia. maternal inheritance of plastid DNA, the absence of gene silencing effects and the possibility of expressing multiple genes as a single polycistronic operon.

The commercial use of plastid transformation for cultivar improvement will ultimately depend on extension of the technology to major crop plant species [8]. Nevertheless, plastid transformants have been produced in a growing number of species including potato $[9,10]$, tomato $[1,11]$, carrot [12], soybean [13], cotton [14], petunia [15] and several members of the Brassicaceae including Arabidopsis thaliana [16], Brassica napus [17] and Lesquerella fendleri [18]. In addition, several promising methods for marker gene excision or generation of marker-free plants from plastid-transformed plants have been demonstrated in tobacco [19-22].

The investigation of alternative DNA delivery strategies, target tissues and regeneration systems has proved crucial for extending the range of species from which plastid transformants can be obtained. In tobacco and tomato, plastid 
transformation is most commonly achieved by biolistic delivery of DNA into leaf explants (e.g. [23,11]), but has also been achieved via direct DNA uptake into protoplasts [24,25,1]. In species other than tobacco, adventitious shoot regeneration from bombarded leaf or petiole explants typically leads to a high number of spontaneous spectinomycin resistant mutants, with a smaller number of plastid transformants [11,15-18], and transformation frequencies are in general much lower than in tobacco. Importantly, however, homoplasmic plants of soybean, carrot and cotton have been obtained at frequencies close to that for tobacco. These plants were regenerated via somatic embryogenesis after bombardment of embryogenic calli, combined with the use of species-specific plastid vectors, conditions that were considered to be significant in minimising the occurrence of spontaneous resistant mutants [12-14]. In these cases, the authors were able to take advantage of welldeveloped embryogenesis systems in which nuclear transformation had been previously demonstrated.

Cauliflower (Brassica oleracea var. botrytis) is one of the most important vegetable brassicas, a group that includes broccoli, cabbage and brussel sprouts. Almost 16 million tonnes of cauliflower were produced worldwide in 2003, with China and India accounting for almost $75 \%$ of this figure [26]. Production of transgenic cauliflower is one possible way to contribute to its genetic improvement. Nuclear transformation of cauliflower has been achieved via Agrobacterium (e.g. [27,28]) and direct DNA uptake into hypocotyl [29,30] or mesophyll protoplasts [31,32].

Plastid transformation of $B$. napus was achieved by biolistic delivery of DNA into cut ends of cotyledonary petioles [17] but was unsuccessful in another study when attempted with PEGmediated uptake into protoplasts or bombardment of protoplast-derived colonies embedded in alginate [33]. However, apart from transient reporter gene expression in broccoli [34], biolistics has not produced transgenic vegetable Brassicas. Furthermore, although biolistics is the most efficient method for plastid transformation, a protoplast system while being more labour-intensive, is cheaper. For these reasons, the current study investigated bombardment of leaves, but focussed mainly on protoplast culture, to obtain both nuclear and plastid transformants in cauliflower. We report an increased nuclear transformation frequency of cauliflower via leaf mesophyll protoplasts and adoption of this protocol for plastid transformation.

\section{Materials and methods}

\subsection{Nuclear transformation vector}

The nuclear transformation vector pGUS-HYG (6.7 kbp) contains the GUS reporter gene, that encodes $\beta$-glucuronidase (GUS) under the control of the Cauliflower Mosaic Virus 35S (CaMV35S) promoter and a selectable marker gene, hygromycin phosphotransferase (hpt) under the control of the Pnos promoter, cloned into a pUC7 backbone. hpt allows for selection of calli and plants resistant to hygromycin.

\subsection{Plastid transformation vector}

The B. napus-specific plastid transformation vector pZB1 $(8.3 \mathrm{kbp})$ was modeled on the tobacco plastid vector pZS197 described in [23]. It was constructed by replacing the left and right flanking regions of $N$. tabacum chloroplast DNA containing the $a c c D$ and $r b c L$ genes, respectively, with the corresponding regions from the B. napus plastome. A 1.3 kbp expression cassette comprising the aadA gene which confers spectinomycin and streptomycin resistance, under the control of tobacco plastid 16SrRNA operon promoter (Prrn) and the $3^{\prime}$-untranslated region of the tobacco plastid gene $p s b A$ [23] was inserted between the B. napus accD and $r b c L$ flanking regions.

A HindIII clone bank covering $97 \%$ of the B. napus chloroplast genome was constructed [35] from which a fragment containing the entire $a c c D$ gene and $494 \mathrm{bp}$ of the $3^{\prime}$ region of $r b c L$ was obtained and fully sequenced. Annealing the following oligonucleotide pair formed a synthetic polylinker, which was inserted into the unique AccI site in the intergenic region adjacent to $r b c L$ for the construction of pZB1:

Acpolf: 5'-ATA CGC GAT CGC CTA GGT CGA CGG GCT TAA GTG ATC ATT AAT TAA GTT TAA AC-3'; AcpolR: 5'-ATG TTT AAA CTT AAT TAA TGA TCA CTT AAG CCC GTC GAC CTA GGC GAT CGC GT-3'.

This polylinker contains the following restriction sites: AccI, SgfI, AvrII, Sal1, AflII, BclI, PacI and PmeI. The Prrn-aadApsbA $3^{\prime}$ spectinomycin/streptomycin resistance cassette was excised from 'pCP7-aadA1' (provided by Alan Magee, Trinty College, Dublin), and cloned into the SalI-AfIII sites of the AcpolIF polylinker.

The final pZB1 vector was then constructed by ligating two gel-purified restriction fragments into the EcoRI site in pUC7: a 980 bp EcoRI-HindIII fragment containing the B. napus $5^{\prime}$ $r b c L$ region and a $4.7 \mathrm{kbp} E c o \mathrm{RI}-H i n d I I I$ fragment containing the $3^{\prime} r b c L$ sequence, the $a a d A$ cassette and the flanking $a c c D$ gene (Fig. 1B).

\subsection{Plant material}

Leaves were obtained from in vitro shoot cultures of $B$. oleracea var. botrytis cv. Thalassa. Seedlings were established from surface sterilised seeds sown in $250 \mathrm{ml}$ containers containing Murashige and Skoog [36] medium (MS) plus 3\% (w/v) sucrose. Shoot cultures were initiated from seedling shoot tips subcultured in containers with the same medium. Protoplasts were isolated from fully expanded leaves of in vitro shoot cultures. Shoot cultures were maintained in Magenta ${ }^{\mathrm{TM}}($ Sigma) containers on growth regulator-free MS medium with $\mathrm{MS}$ vitamins containing $30 \mathrm{~g} / \mathrm{l}$ sucrose, at $25{ }^{\circ} \mathrm{C}$ under a $(16 \mathrm{~h}$ light $/ 8 \mathrm{~h}$ dark $)$ light regime. Shoot cultures were grown for up to three 4-week subcultures before fresh cultures were initiated from 10-dayold seedlings. 

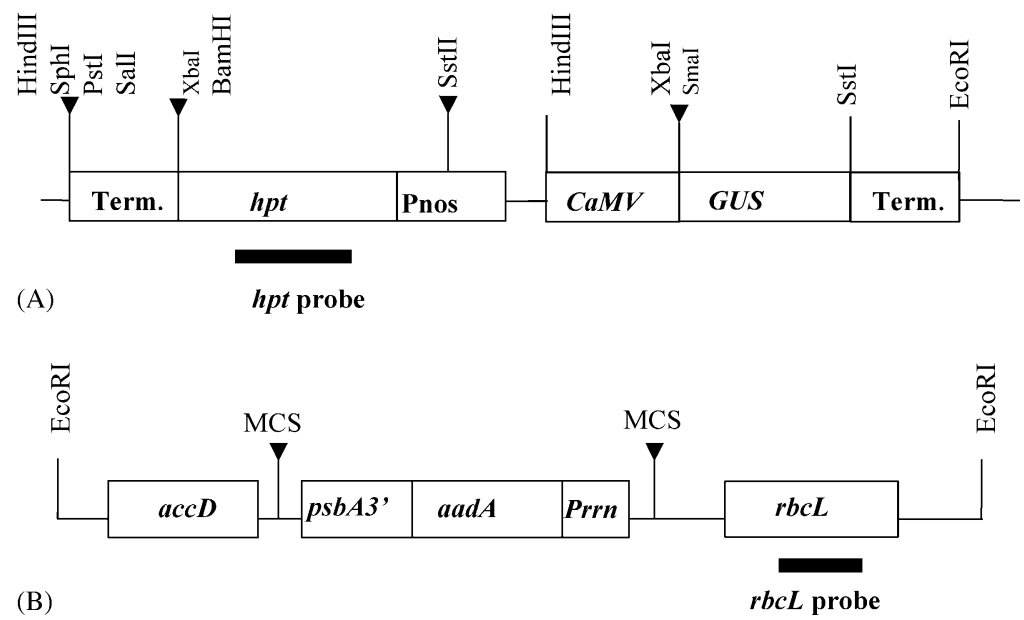

Fig. 1. Schematic maps of the nuclear and plastid transformation vectors and position of the probes used for Southern blot analyses: (A) genetic map of the insert of the pGUS-HYG plasmid (6.7 kbp). Term: terminator; Pnos: nopaline synthase gene promoter; GUS: $\beta$-glucuronidase gene; hpt: hygryomycin phosphotransferase gene; CaMV: CAMV35S promoter. (B) Brassica plastid transformation vector pZB1 (8.3 kbp), with the chimeric aadA expression cassette cloned between left and right flanking plastid DNA sequences. $a c c D$ : $\beta$-subunit acetyl-CoA carboxylase gene; MCS: multiple cloning site; rbcL: rubisco large subunit gene; aadA: aminoglycoside $3^{\prime \prime}$-adenylyltransferase gene; Prrn: plastid rRNA-operon promoter; $p s b A 3^{\prime}: 3^{\prime}$ untranslated region of the gene encoding the D1 polypeptide of photosystem II.

\subsection{Protoplast isolation}

Protoplasts were isolated and cultured according to a protocol modified from [37]. One gram of the youngest fully expanded leaves were finely sliced then cultured in preplasmolysis medium (PG: sorbitol $54.66 \mathrm{~g} / 1, \mathrm{CaCl}_{2} \cdot 2 \mathrm{H}_{2} \mathrm{O}$ $7.35 \mathrm{~g} / \mathrm{l})$ for $1-2 \mathrm{~h}$ in the dark at $4{ }^{\circ} \mathrm{C}$. After preplasmolysis, PG-medium was replaced by $20 \mathrm{ml}$ of enzyme solution [B-medium (modified from [37]), see below] with $0.1 \%$ cellulase Onozuka R10, $0.25 \%$ macerozyme Onozuka $\mathrm{R} 10)$. Leaf strips were incubated overnight in $125 \mathrm{ml}$ glass flasks in darkness on a rotary shaker at $40 \mathrm{rpm}$ at $22{ }^{\circ} \mathrm{C}$. The protoplast suspension was filtered through $50 \mu \mathrm{m}$ nylon mesh and collected in a $15 \mathrm{ml}$ tube. Per tube, about $2.5 \mathrm{ml}$ of CPW solution [38] containing 16\% (w/v) sucrose was added and mixed. On top of this solution, $1 \mathrm{ml}$ of W5 solution was layered [39], after which the tubes were centrifuged for $8 \mathrm{~min}$ at $70 \times \mathrm{g}$. Protoplasts were collected as a band between the two solutions, and transferred to a new tube. The volume was brought to $10 \mathrm{ml}$ with W5 and then centri- fuged $(5 \mathrm{~min}$ at $60 \times \mathrm{g}$ ) to pellet the protoplasts. The wash in W5 was repeated twice. Protoplasts were resuspended in B-medium, centrifuged $(5 \mathrm{~min}$ at $60 \times \mathrm{g})$ and re-collected in B-medium, then diluted to a concentration of $10^{5}$ protoplasts $/ \mathrm{ml}$. The protoplast density was determined with a haemocy- tometer.

\subsection{Protoplast transformation and selection of transformants}

Freshly isolated protoplasts were resuspended in MgMann transformation buffer [40] at $1.0 \times 10^{6}$ protoplasts $/ \mathrm{ml}$. Each transformation replicate was carried out in a $500 \mu \mathrm{l}$ volume (representing approximately half a million protoplasts) in $15 \mathrm{ml}$ centrifuge tubes (Greiner). Plasmid DNA was added to protoplasts to a final concentration of $60 \mu \mathrm{g} / \mathrm{ml}$ (pGUS-
HYG) or $200 \mu \mathrm{g} / \mathrm{ml}$ (pZB1) for nuclear or plastid transformation treatments, respectively. An equal volume of $40 \%$ (w/ v) polyethylene glycol (PEG4000) [40] was added drop-wise, the mixture gently swirled then left to sit for $15 \mathrm{~min}$. W5 solution was added to the tube to bring the volume to $10 \mathrm{ml}$ and then the tubes were centrifuged at $60 \times g$ for $5 \mathrm{~min}$ to pellet the protoplasts. Protoplasts were washed a second time in W5 then resuspended in liquid B-medium to a concentration of $1.0 \times 10^{5}$. Protoplasts were then mixed with an equal volume of $2 \times$ B-medium mixed with $4 \%$ (w/v) low melting point agarose (SeaPlaque), cooled to $50{ }^{\circ} \mathrm{C}$. Four milliliters aliquots of the protoplast/agarose mixture were poured into $6 \mathrm{~cm}$ petri dishes to set the agarose, giving a final plating protoplast density of $5 \times 10^{4} \mathrm{pps} / \mathrm{ml}$. Then agarose discs were cut into four equal sectors and two sectors cultured per $9 \mathrm{~cm}$ petri dish with $8 \mathrm{ml}$ of liquid B-medium. Petri dishes were cultured at $25^{\circ} \mathrm{C}$ in darkness for the first 10 days after transformation, then under low light. After 2 weeks, the cultures were grown under full light $(16 \mathrm{~h}$ light period, approximately $4000 \mathrm{~lx}$ ).

The protoplasts were cultured on a series of media (B, C, E, F) modified from [37]. Media B, C and D were filter sterilised and media E, F and $\mathrm{G}$ were autoclaved. Several modifications were made to the published media [37]. Morpholinoethanesulphonic acid (MES) $(0.1 \mathrm{~g} / \mathrm{l})$ was added to media B, C, D: $1 \mathrm{mg} / \mathrm{l} 2 \mathrm{iP}$ was used in medium $\mathrm{E}$ instead of IPA, $6 \mathrm{~g} / \mathrm{l}$ agar was used in media E, F and $\mathrm{G}$ instead of $8 \mathrm{~g} / \mathrm{l}$, Tween 80 was omitted from medium $\mathrm{B}$ and agarose embedding of protoplasts was used instead of culture in liquid. All plant growth regulators and antibiotics were added to media after autoclaving from filtersterilised stocks.

After 10 and 20 days, $4 \mathrm{ml}$ of medium was pipetted out of each petri dish and $4 \mathrm{ml}$ fresh medium was added with the following composition: after 10 days, $4 \mathrm{ml}$ medium $\mathrm{C}$ was added, and after 20 days $4 \mathrm{ml}$ medium $\mathrm{D}$ was added. Ten days 
after plating, four to eight cell clusters were visible and 20 days after plating micro-calli were visible macroscopically. The antibiotics hygromycin $(10 \mathrm{mg} / \mathrm{l})$ or spectinomycin $(60 \mathrm{mg} / \mathrm{l})$ was added to cultures at 10 days. Calli, at least $2 \mathrm{~mm}$ in size were eventually transferred to solid medium $E$ with the relevant selection regime and transferred every $2-4$ weeks to fresh medium E. Regenerating plantlets were transferred to medium $\mathrm{F}$ (shoot outgrowth) and subsequently for rooting to medium G, prior to transfer to soil. Five nuclear transformation experiments comprising 1 milllion protoplasts each and six plastid transformation experiments comprising up to 3 million protoplasts each were carried out.

\subsection{GUS assay and leaf disc assay}

Protoplast calli on medium E and leaf pieces from regenerants produced in pGUS-HYG transformation experiments were tested for GUS expression histochemically [41]. Sterile leaf pieces of the plastid transformant and nontransformed shoots were tested for spectinomycin resistance by culture on brassica shoot regeneration medium (MS medium with $44 \mu \mathrm{M}$ BA, $4.4 \mu \mathrm{M}$ NAA, $5 \mathrm{mg} / \mathrm{l} \mathrm{AgNO}_{3}, 300 \mathrm{mg} / \mathrm{l}$ spectimomycin).

\subsection{Molecular analyses}

Genomic DNA was extracted from leaves or calli using the method described by [42]. Southern hybridization was performed using the DIG DNA Labeling and Detection Kit (Boehringer Mannheim, Mannheim, Germany).

The primer pairs for analysis of nuclear transformants were 5'-CCTGTAGAAACCCCAACCCGTG- $3^{\prime}$ and $5^{\prime}$-CCCGGCAATAACATACGGCGTG-3' ${ }^{\prime}$ to amplify a 365 bp product from the GUS gene and $5^{\prime}$ - AGCTGC GCCGATGGTTTCTACAA- $3^{\prime}$ and $5^{\prime}$-ATCGCCTCGCTCCAGTCAATG- $3^{\prime}$ to amplify a $508 \mathrm{bp}$ fragment from the hpt gene. PCR was carried out using AmpliTaq polymerase. The initial denaturation was done at $94{ }^{\circ} \mathrm{C}$ for $5 \mathrm{~min}$; this was followed by 35 cycles of $94{ }^{\circ} \mathrm{C}$ (denaturing), $1 \mathrm{~min}$ at $55^{\circ} \mathrm{C}$ (annealing) and $2 \mathrm{~min}$ at $72{ }^{\circ} \mathrm{C}$ (extension). A final extension at $72{ }^{\circ} \mathrm{C}$ for $10 \mathrm{~min}$ was included. The amplified products were visualised by electrophoresis on $0.8 \%$ (w/v) agarose gels stained with ethidium bromide.

Putative plastid transformants analysed by PCR with various pairwise combinations of 5 primers. Two were specific for the chimeric aadA (primers $2+3$ ), one for Prrn (1), one for $r b c L$
(5) and one for $a c c D$ (4). The $r b c L$ and $a c c D$ primers were designed outside the vector sequence. Promoter genes and analysis for homoplasmy used a pair of primers (RBCL/ACCD) or flanking the transgene insertion site in the brassica chloroplast genome. Primers used for screening transformants and probe synthesis were as follows: Prrn (1) 5'-CTAGTTGGATTTGCTCCCCGCCG-3', aadA (2) 5'-ATCGCCGAAGTATCAAGTCA-3'; aadA (3) $5^{\prime}$-TGACGGGGCTGATACTGGGCCG-3'; rbcL (5) 5'-CAGAGACTAAAGCAAGTGTTG3'; accD (4) 5'-CATGTCTTCATCCATAGGA; rbcLF 5'GTCTACTTCTTCACATCCACC-3'; rbcLR 5'-TCCATACTTCACAAGCAGC- $3^{\prime}$.

PCR was performed with the AccuTaq kit (Sigma) as follows: initial denaturing $94{ }^{\circ} \mathrm{C} 2 \mathrm{~min}$, then 30 cycles of denaturing $94{ }^{\circ} \mathrm{C}$ for $30 \mathrm{~s}$ (denaturing), $51-63{ }^{\circ} \mathrm{C}$ (annealing, depending on the $\mathrm{Tm}) 15 \mathrm{~s}$ and $68^{\circ} \mathrm{C}$ for $4-6 \mathrm{~min}$ (extension).

For Southern blot analysis, 5-7 $\mu \mathrm{g}$ of total DNA were digested with $E c o$ RI for nuclear transformants and $E c o$ RI and EcoRV for plastid transformants, separated in $0.8 \%$ (w/v) agarose gels $(16 \mathrm{~h}, 25-30 \mathrm{~V})$ and transferred to a nylon membrane (Hybond $\mathrm{N}^{+}$; Amersham). Signal detection was performed using a non-radioactive DNA labelling [43] and detection protocol (DIG Probe Synthesis Kit, Roche, Mannheim, Germany). For nuclear transformants, the probe was a $h p t$ gene fragment, generated by PCR. For plastid transformant analysis, pZB1 was used as the template to synthesize an $r b c L$ probe using the primers RB197F and RB197R. The probes were labelled with DIG-dUTP (Roche Diagnostics, Germany) by PCR. Following hybridization and stringent washing of membranes, the hybridized probe was detected using an anti-DIG antibody and a chemiluminescent substrate (CDPstar, Roche). Signals were visualised by exposure to Kodak Xray film for $1-5 \mathrm{~min}$.

\section{Results and discussion}

\subsection{Nuclear transformation}

Routine protoplast isolation, culture and shoot regeneration was established for cv. Thalassa, based on a modified protocol from [37]. Several factors, such as agarose embedding versus liquid culture of protoplasts and tissue sources of protoplasts were investigated in protoplast culture experiments (data not shown).

Table 1

Division and transformation frequencies in nuclear transformation experiments

\begin{tabular}{llllll}
\hline Experiment number & Control & Control PEG & pGUS-HYG $\left(0{ }^{\circ} \mathrm{C}\right)$ & pGUS-HYG $\left(25^{\circ} \mathrm{C}\right)$ & Absolute transformation frequency \\
\hline 1 & 9.8 & 7.8 & 6.2 & 7.2 & $0.3 \times 10^{-5}$ \\
2 & 28.7 & $\mathrm{n} / \mathrm{r}$ & 28.5 & 19.1 & $1.2 \times 10^{-5}$ \\
3 & 41.2 & $\mathrm{n} / \mathrm{r}$ & 32.5 & 24.9 & $1.0 \times 10^{-5}$ \\
4 & 30.1 & 29.5 & 22 & 20.4 & $1.2 \times 10^{-5}$ \\
Mean & 27.5 & - & 22.3 & 17.9 &
\end{tabular}

Values are percent of protoplasts, which had divided 10-12 days after protoplast isolation. At least 400 protoplasts were scored for each treatment. Absolute transformation frequency is the number of transgenic calli or shoots per number of treated protoplasts; $\mathrm{n} / \mathrm{r}$ : not recorded. 

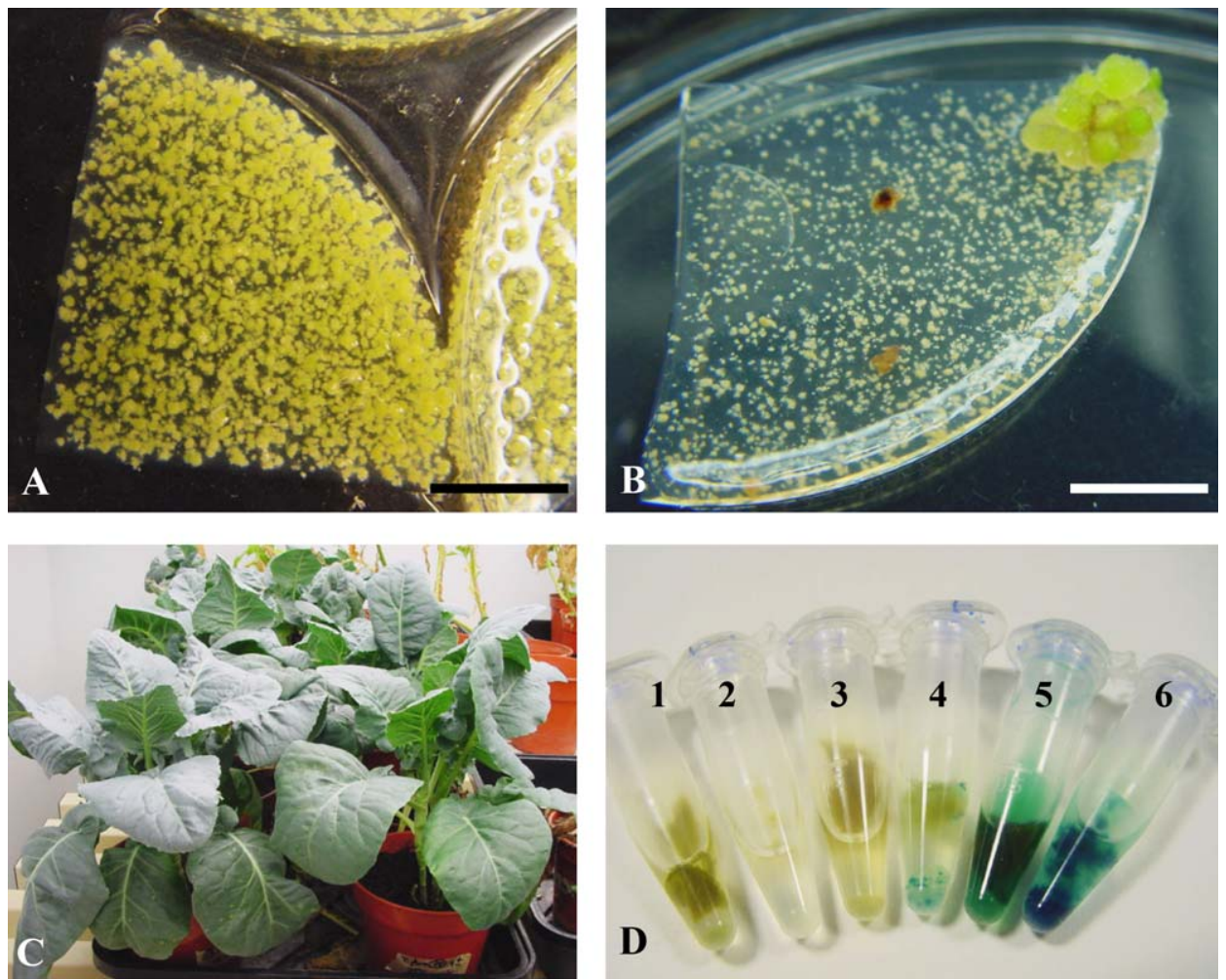

Fig. 2. Generation of cauliflower nuclear transformants with pGUS-HYG: (A) control protoplast colonies in agarose at 30 days $($ bar $=1 \mathrm{~cm}) ;(B)$ Hyg ${ }^{\mathrm{r}}$ embryos at 45 days $(\mathrm{bar}=1 \mathrm{~cm})$; $(\mathrm{C})$ transgenic plants in soil; (D) range of GUS activity in different transgenic plants (tube 1: non-transgenic, tubes 2 and 3: GUS negative transgenics and tubes 4-6: GUS positive transgenics).

Transgenic calli and shoots were recovered in all four experiments using the protoplast culture protocol combined with direct DNA uptake via PEG treatment [40]. Addition of PEG reduced the protoplast division frequency in all experiments compared with controls, but less so when the protoplast/PEG/plasmid mixtures were incubated on ice during the $15 \mathrm{~min}$ transformation period (Table 1). However, the absolute transformation frequencies were not different between the two temperatures at the end of the experiments. Division frequency of hypocotyl protoplasts of an Indian cauliflower cultivar were reduced by an average of $28 \%$ with PEG treatment and an average of $65 \%$ when exposed to PEG and vector DNA [29]. Our data showed that division frequency of mesophyll protoplasts transformed at $25{ }^{\circ} \mathrm{C}$ was reduced by $33 \%$ compared to untreated control protoplasts (Table 1). Hygromycin resistant colonies and plants (Fig. 2) were recovered in all experiments. The absolute transformation frequency (ratio of resistant colonies/shoots per the number of treated protoplasts) ranged from $(0.3$ to 1.3$) \times 10^{-5}$. This is lower than reported for cauliflower hypocotyl protoplasts $[29,30]$ but much higher than previously obtained for cauliflower mesophyll protoplasts $\left(5 \times 10^{-7}[32]\right)$. A range of GUS expression levels was evident in calli and leaves from different transformants (Fig. 2D). PCR products of the expected size were obtained for both GUS and $h p t$ (Fig. 3A). Overall the hpt PCR appeared to be more efficient in detecting transformants than the use of GUS primers
(Table 2). Southern blot analysis further showed that four out of nine nuclear transgenics contained the hpt gene as a single copy fragment (Fig. 3B).

\subsection{Plastid transformation}

In a series of preliminary experiments, biolistic transformation of cauliflower was attempted with pZB1 in 110 shots of leaf tissue from in vitro shoots (data not shown). No plastid transformants or spontaneous spectinomycin resistance mutants were obtained. Only bleached plastid ribosome deficient shoots (PRD), previously identified and characterised in B. napus [44] were obtained. In contrast, in protoplast transformation experiments, spontaneous spectinomycin resistant mutants, usually the vast majority of shoots regenerated from tobacco, potato and more recently in $B$.

Table 2

Results of selection for hygromycin resistant calli/shoots after transformation with pGUS-HYG

\begin{tabular}{ll}
\hline GUS assay & $76 \%(n=67)$ \\
GUS PCR products & $44 \%(n=39)$ \\
hpt PCR products & $75 \%(n=39)$ \\
hpt Southern & $100 \%(n=9)$ \\
\hline
\end{tabular}

Results of GUS histochemical assay, PCR using GUS or $h p t$ primers and a Southern blot analysis using a $h p t$ probe. (Percent positive results, $n$ is number of calli/shoots assayed or screened.) 


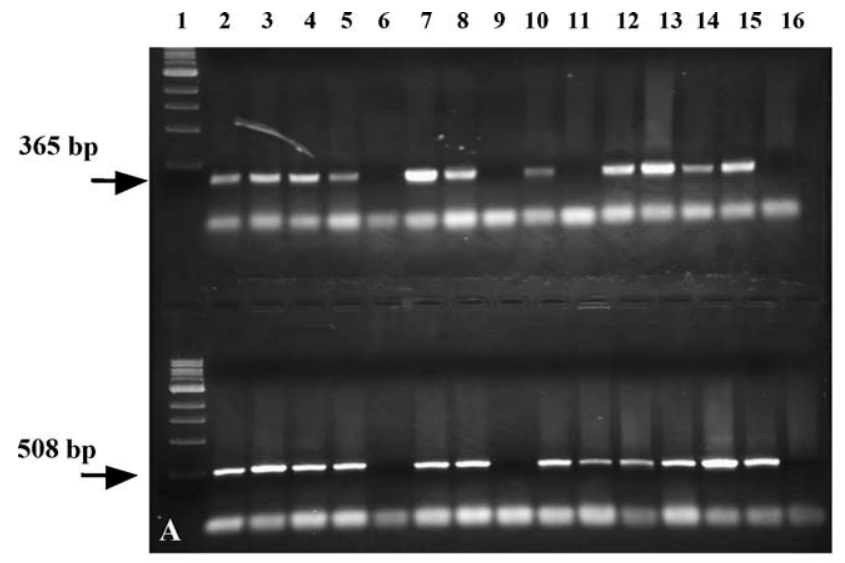

$\begin{array}{llllllllllll}1 & 2 & 3 & 4 & 5 & 6 & 7 & 8 & 9 & 10 & 11 & 12\end{array}$

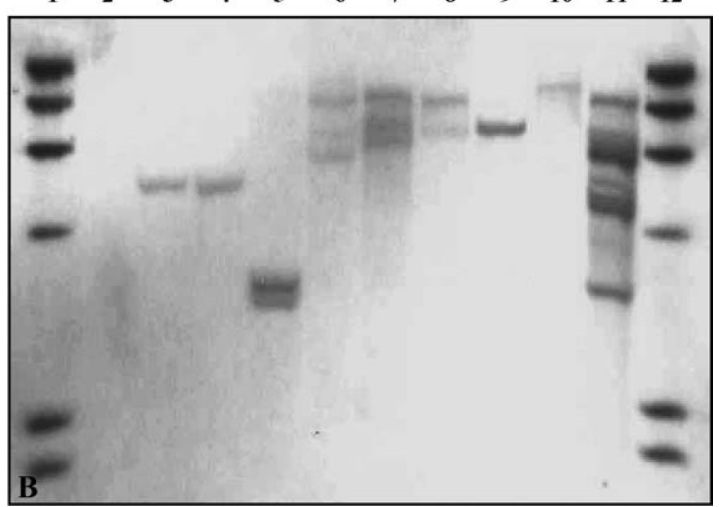

Fig. 3. Molecular analysis of cauliflower nuclear transformants: (A) PCR analysis of $\mathrm{Hyg}^{\mathrm{r}}$ calluses and shoots transformed with pGUS-HYG using GUS primers (365 bp product) (upper lanes) and $h p t$ primers (508 bp product) (lower lanes). Lane 1: $1 \mathrm{kbp}$ ladder; lanes 2-15: $\mathrm{Hyg}^{\mathrm{r}}$ callus lines or shoots; lane 16: wild type. (B) Southern blot of cauliflower EcoRI digested genomic DNA hybridised with an hpt probe. Lanes 1 and 12: $\lambda$ HindIII marker; lane 2: wild type; lanes 3-11: $\mathrm{Hyg}^{\mathrm{r}}$ shoots.

napus under spectinomycin selection [17] were not observed. Green shoots were obtained from protoplast calli (p-calli), but only when spectinomycin selection was removed after 1 month (Table 3). Subsequent culture of these shoots on spectinomycincontaining medium showed that none were resistant or transgenic. Culture of calli for 2 months or more on spectinomycin medium prevented recovery of green shoots after subsequent removal of selection (Table 3).

\section{Table 3}

Responses of protoplast calli in a plastid transformation experiment to 1,2 or at least 4 months (continuous) selection on spectinomycin medium $(60 \mathrm{mg} / \mathrm{l})$

\begin{tabular}{lcccc}
\hline Treatment & $\begin{array}{l}\text { Senescent } \\
(\%)\end{array}$ & $\begin{array}{l}\text { Green } \\
(\%)\end{array}$ & $\begin{array}{l}\text { Shoots } \\
(\%)\end{array}$ & $\begin{array}{l}\text { Roots } \\
(\%)\end{array}$ \\
\hline Control (0 spec) & 8 & 53 & 41 & 72 \\
Control/continuous spec & 100 & 0 & 0 & 6 \\
pZB1/spec 1 month then 0 spec & 0 & 74 & 18 & 80 \\
pZB1/spec 2 month then 0 spec & 77 & 0 & 0 & 0 \\
pZB1/continuous spec & 85 & 0 & 0 & 1.3 \\
\hline
\end{tabular}

No green calli were formed in culture following spectinomycin treatments (Table 3) and as little as $10 \mathrm{mg} / \mathrm{l}$ spectinomycin prevented greening of p-calli. Spectinomycin was used at $20-60 \mathrm{mg} / \mathrm{l}$ in the 5 plastid transformation experiments. Embryogenic p-calli were only obtained in long-term culture with spectinomycin selection, when the growth regulators in the medium were altered. The medium in the original protocol was designed for shoot regeneration from p-calli in control (non-spec) treatments, and was not suitable for long-term callus culture.

Plasmid DNA was added at $200 \mu \mathrm{g} / \mathrm{ml}$ of protoplasts in plastid transformation experiments. A single plastid-transformed callus was obtained, 5 months after a transformation experiment in which 3 million protoplasts were cultured. Prior to this experiment, calli were kept for only 3-4 months before termination of the experiment. This callus subsequently gave rise to many shoot-like structures and eventually normal shoots (Fig. 4A). Leaf explants from these regenerated shoots placed on shoot regeneration medium containing spectinomycin regenerated further resistant shoots (Fig. 4B). PCR analyses using an internal transgene-based primer pair $(1+2)$ or an internal (3) and an external primer (4) amplified a product in DNA samples from spectinomycin-resistant callus but not in wild-type samples, indicating the presence of the aadA expression cassette in the plastome of the former (Fig. 4C). When external primers $(4+5)$ alone were used, a major PCR product was amplified in the transformant that was $1.3 \mathrm{kbp}$ larger than the major product amplified in wild-type cauliflower samples $(5+4)$ (Fig. 4C), thus confirming plastome-specific insertion of the aadA cassette between the $r b c L$ and $a c c D$ genes. However, genomic DNA from the transplastidic callus also produced as a minor PCR product, a product characteristic of the wild-type plastome, suggesting that homoplasmy had not yet been achieved. Several months continued culture produced further clones of the callus from which shoots were recovered. Southern blot analysis showed that after this prolonged culture period, both callus and shoots were homoplasmic for the aadA cassette (Fig. 4D).

The low plastid transformation frequency obtained in cauliflower may be partly due to a sub-optimal protoplast division frequency, insufficient for the recovery of rare transformation events. The use of a transformation vector containing $B$. napus plastid DNA that may not be completely homologous to the $B$. oleracea plastome in the targeted region may also be a contributing factor. Several papers have shown that plastid transformation of tobacco is possible with vectors containing targeting flanking regions of ptDNA of other species (e.g. [45]), but at lower efficiency than with vectors containing tobacco ptDNA. Recent reports have shown that species-specific vectors have contributed to efficient plastid transformation in carrot, cotton and soybean $[12,14]$. The site of integration of the plastid transformation vector might also be an important determinant of the plastid transformation frequency.

This is the first report of plastid transformation in a vegetable brassica and extends the use of protoplasts for plastid transformation to a non-solanaceous crop. 

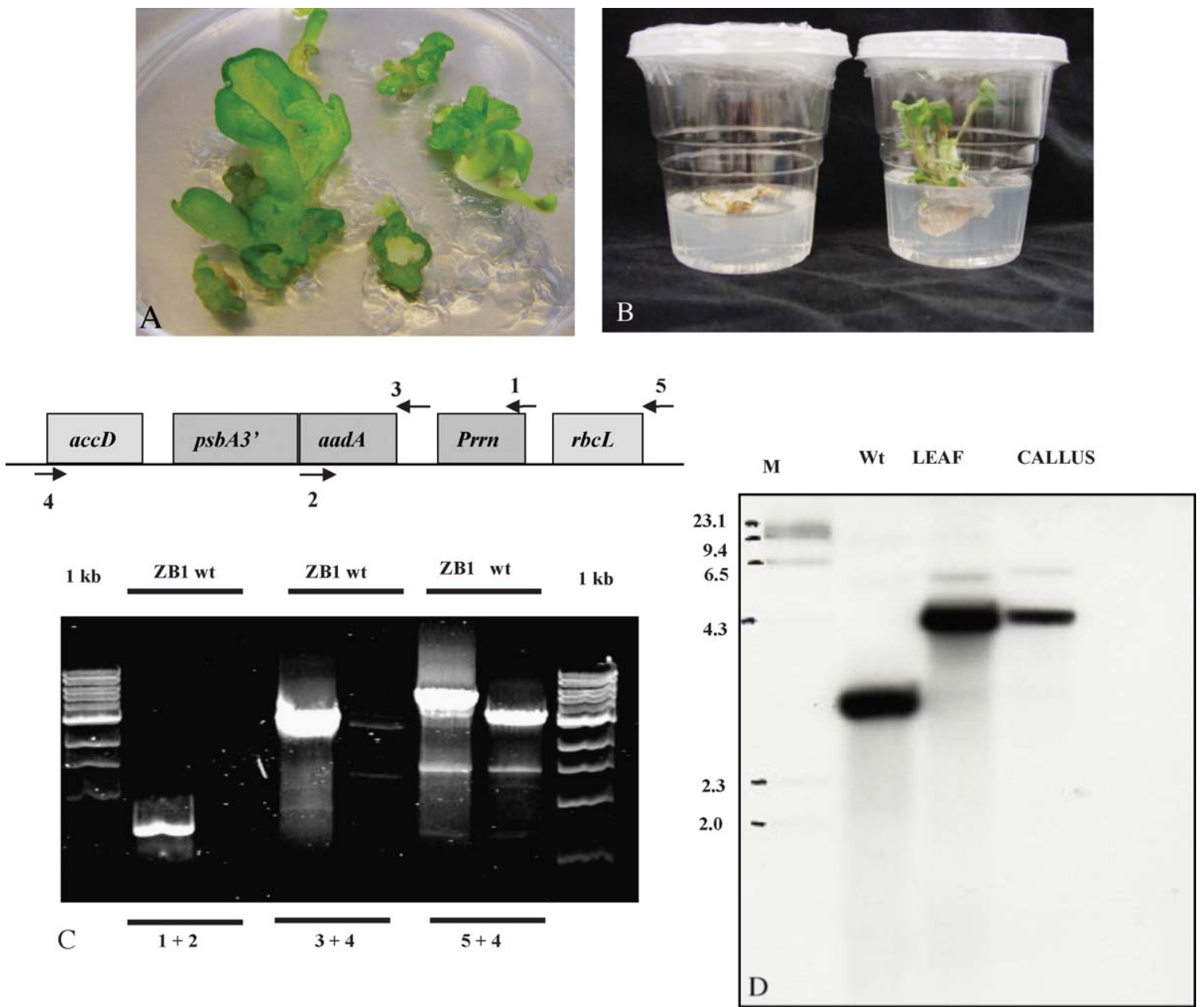

Fig. 4. Regeneration and molecular analysis of a cauliflower plastid transformant: (A) shoots derived from transplastidic callus on medium E; (B) culture of leaf pieces from wild type (left) and plastid transformant on shoot regeneration medium containing $300 \mathrm{mg} / \mathrm{l}$ spectinomycin; (C) PCR analysis of spec ${ }^{\mathrm{r}}$ transplastidic callus using primers internal to pZB1 $(1+2)$, a combination of an internal and external primer $(3+4)$, and two external primers $(5+4)$. The external primer pair amplify a larger sized PCR product from transplastidic callus (ZB1) compared with wild-type callus (wt). (D) Southern blot analysis of total DNA extracted from wild-type (Wt) and transplastidic leaf and callus tissue following digestion with both EcoRI and EcoRV. The blot was hybridized with a DIG-labelled $r b c L$ probe; M: $\lambda$ HindIII DNA marker.

\section{Acknowledgements}

This study was funded by a European Union 5th Framework grant, QLK3CT199900692. Our thanks to Dr. Cilia Lelivelt, Rijk Zwaan Breeding BV, Netherlands, for demonstration of Brassica protoplast isolation and culture.

\section{References}

[1] G.D. Nugent, M. ten Have, A. van der Gulik, P.J. Dix, B.A. Uijtewaal, A.P. Mordhorst, Plastid Transformants of Tomato selected using mutations affecting ribosome structure, Plant Cell Rep. 24 (2005) 341-349.

[2] M. Sugita, Z. Svab, P. Maliga, M. Sugiura, Targeted deletion of sprA from the tobacco plastome indicates that the encoded small RNA is not essential for pre-16S rRNA maturation in plastids, Mol. Gen. Genet. 257 (1997) 23-27.

[3] R. Bock, Transgenic plastids in basic research and plant biotechnology, J. Mol. Biol. 312 (2001) 425-438.

[4] H. Daniell, M.S. Khan, L. Allison, Milestones in chloroplast genetic engineering: an environmentally friendly era in biotechnology, Trends Plant Sci. 7 (2002) 84-91.

[5] P. Maliga, Progress towards commercialization of plastid transformatino technology, Trends Biotechnol. 21 (2003) 20-28.
[6] P. Maliga, Plastid transformation in higher plants., Ann. Rev. Plant Physiol. Plant Mol. Biol. 55 (2004) 289-313.

[7] P.B. Heifetz, Genetic engineering of the chloroplast, Biochemie 82 (2000) 655-666.

[8] P. Maliga, Engineering the plastid genome of higher plants, Curr. Opin. Plant Biol. 5 (2002) 164-172.

[9] V.A. Sidorov, D. Kasten, S.Z. Pang, P.T.J. Hajdukiewicz, J.M. Staub, N.S. Nehra, Stable chloroplast transformation in potato: use of green fluorescent protein as a plastid marker, Plant J. 19 (1999) 209-216.

[10] T.T. Nguyen, G. Nugent, T. Cardi, P.J. Dix, Generation of homoplasmic plastid transformants of a commercial cultivar of potato (Solanum tuberosum L.), Plant Sci. 168 (2005) 1495-1500.

[11] S. Ruf, M. Hermann, I.J. Berger, H. Carrrer, R. Bock, Stable genetic transformation of tomato plastids and expression of a foreign protein in fruit, Nat. Biotechnol. 19 (2001) 870-875.

[12] S. Kumar, A. Dhingra, H. Daniell, Plastid-expressed betaine aldehyde dehydrogenase gene in carrot cultured cells, roots, and leaves confers enhanced salt tolerance, Plant Physiol. 136 (2004) 2843-2854.

[13] N. Dufourmantel, B. Pwlissier, F. Garcon, G. Peltier, J.M. Ferullo, G. Tissot, Generation of fertile transplastomic soybean, Plant Mol. Biol. 55 (2004) 479-489.

[14] S. Kumar, A. Dhingra, H. Daniell, Stable transformation of the cotton plastid genome and maternal inheritance of transgenes, Plant Mol. Biol. 56 (2004) 203-216. 
[15] M.K. Zubko, E.I. Zubko, K. van Zuilen, P. Meyer, A. Day, Stable transformation of petunia plastids, Transgenic Res. 13 (2004) 523-530.

[16] S.R. Sikdar, G. Serino, S. Chaudhuri, P. Maliga, Plastid transformation in Arabidopsis thaliana, Plant Cell Rep. 18 (1998) 20-24.

[17] B.K. Hou, Y.H. Zhou, L.H. Wan, Z.L. Zhang, G.F. Shen, Z.H. Chen, Z.M. $\mathrm{Hu}$, Chloroplast transformation in oilseed rape, Trans. Res. 12 (2003) 111114.

[18] M. Skarjinskaia, Z. Svab, P. Maliga, Plastid transformation in Lesquerella fendleri, an oilseed Brassicacea, Trans. Res. 12 (2003) 115-122.

[19] S. Iamtham, A. Day, Removal of antibiotic resistance genes from transgenic tobacco plastids, Nat. Biotechnol. 18 (2000) 1172-1176.

[20] S. Corneille, K. Lutz, Z. Svab, P. Maliga, Efficient elimination of selectable marker genes from the plastid genome by the CRE-lox sitespecific recombination system, Plant J. 27 (2001) 171-178.

[21] P.T.J. Hajdukiewitz, L. Gilbertson, J.W. Staub, Multiple pathways for Cre/ lox-mediated recombination in plastids, Plant J. 27 (2001) 161-170.

[22] S.M.J. Klaus, F.-C. Huang, T.J. Golds, H.-U. Koop, Generation of markerfree plastid transformants using a transiently cointegrated selection gene, Nat. Biotechnol. 22 (2004) 225-229.

[23] Z. Svab, P. Maliga, High-frequency plastid transformation in tobacco by selection for a chimeric aadA gene, PNAS 90 (1993) 913-917.

[24] T.J. Golds, P. Maliga, H.-U. Koop, Stable plastid transformation in PEGtreated protoplasts of Nicotiana tabacum, Bio/Technology 11 (1993) 95-97.

[25] C. O’Neill, G.V. Horváth, E. Horváth, P.J. Dix, P. Medgyesy, Chloroplast transformation in plants: polyethylene glycol (PEG) treatment of protoplasts is an alternative to biolistic systems, Plant J. 3 (1993) 729-738.

[26] FAOSTAT, Statistical Database of the Food and Agriculture Organization of the United Nations, 2003 (http://www.fao.org/waicent/portal/statistics_en.asp, last updated 20 December 2004).

[27] C. David, J. Tempé, Genetic transformation of cauliflower (Brassica oleracea L. var. botrytis) by Agrobacterium rhizogenes, Plant Cell Rep. 7 (1988) 88-91.

[28] P.L. Bhalla, N. Smith, Agrobacterium tumefaciens-mediated transformation of cauliflower, Brassica oleracea var. botrytis, Mol. Breed. 4 (1998) 531-541.

[29] A. Mukhopadhyay, R. Töpfer, A.K. Pradhan, Y.S. Sodhi, H.H. Steinbiß, J. Schell, D. Pental, Efficient regeneration of Brassica oleracea hypocotyl protoplasts and high frequency genetic transformation by direct DNA uptake, Plant Cell Rep. 10 (1991) 375-379.

[30] H.-W. Xue, Z.-M. Wei, Z.-H. Xu, Regeneration of transgenic plants of Brassica oleracea via PEG-mediated gene transformation, Acta Bot. Sin. 39 (1997) 28-33 (in Chinese).
[31] K. Eimert, F. Siegemund, Transformation of cauliflower (Brassica oleracea L. var. botrytis) — an experimental survey, Plant Mol. Biol. 19 (1992) 485-490.

[32] V.V. Radchuk, U. Ryschka, G. Schumann, E. Klocke, Genetic transformation of cauliflower (Brassica oleracea var. botrytis) by direct DNA uptake into mesophyll protoplasts, Physiol. Plant 114 (2002) 429-438.

[33] A. Dovzhenko, Towards plastid transformation in rapeseed (Brassica napus L.) and sugarbeet (Beta vulgaris L.), Ph.D. Thesis, Department Biology, Ludwig Maximilians University, Munich, Germany, 2001.

[34] I.J. Puddephat, N. Thompson, H.T. Robinson, P. Sandhu, J. Henderson, Biolistic transformation of broccoli (Brassica oleracea var. italica) for transient expression of the $\beta$-glucuronidase gene, J. Hort. Sci. Biotechnol. 74 (1999) 714-720.

[35] S. Coyne, Transformation and marker gene removal strategies for the plastid genome of Brassica napus, Ph.D Thesis, University of Dublin, Trinity College, 2002.

[36] T. Murashige, F. Skoog, A revised medium for rapid growth and bioassays with tobacco cultures, Physiol. Plant 15 (1962) 473-498.

[37] G. Pelletier, C. Primard, F. Vedel, P. Chétrit, R. Rémy, M. Renard, Intergeneric cytoplasmic hybridization in Cruciferae by protoplast fusion, Mol. Gen. Genet. 191 (1983) 244-250.

[38] F.M. Frearson, J.B. Power, E.C. Cocking, The isolation, culture and regeneration of Petunia leaf protoplasts, Dev. Biol. 33 (1973) 130-137.

[39] L. Menczel, F. Nagy, Z.S. Kiss, P. Maliga, Streptomycin resistant and sensitive somatic hybrids of Nicotiana tabacum and Nicotiana knightiana: correlation of resistance to N. tabacum plastids, Theor. Appl. Gen. 59 (1981) 191-195.

[40] W. Kofer, C. Eibl, K. Steinmüller, H.-U. Koop, Review: PEG-mediated plastid transformation in higher plants, In Vitro Cell Dev. Biol. Plant 34 (1998) 303-309.

[41] R.A. Jefferson, T.A. Kavanagh, M.W. Bevan, GUS fusions: $\beta$-glucuronidase as a sensitive and versatile gene fusion marker in higher plants, EMBO J. 6 (1987) 3091-3097.

[42] J.E. Frey, Genetic flexibility of plant chloroplasts, Nature 398 (1999) 115116.

[43] M.S. McCabe, J.B. Power, A.M.M. De Laat, M.R. Davey, Detection of single-copy genes in DNA from transgenic plants by non-radioactive Southern blot analysis, Mol. Biotechnol. 7 (1997) 79-84.

[44] M.K. Zubko, A. Day, Stable albinism induced without mutagenesis: a model for ribosome-free plastid inheritance, Plant J. 15 (1998) 265-271.

[45] G. DeGray, K. Rajasekaran, F. Smith, J. Sanford, H. Daniell, Expression of an antimicrobial peptide via the chloroplast genome to control phytopathogenic bacteria and fungi, Plant Physiol. 127 (2001) 852-862. 